American Journal of Immunology 2 (2): 52-57, 2006

ISSN 1553-619X

(C) 2006 Science Publications

\title{
Leishmania donovani: Immunomodulatory Role of 63KDa Leishmania Antigen in the Promotion of IFN-gamma Response (VL vs HIV-VL Co-infection)
}

\author{
${ }^{2}$ Pranati, ${ }^{1}$ Sanjiva Bimal, ${ }^{1}$ K.Pandey, ${ }^{1}$ P.K.Sinha, ${ }^{1}$ A.K.Gupta, ${ }^{1}$ Shubhankar K.Singh \\ ${ }^{2}$ Shanthy Sundaram and ${ }^{1}$ P.Das \\ ${ }^{1}$ Rajendra Memorial Research Institute of Medical Sciences (ICMR), Agamkuan, Patna-800007, India \\ ${ }^{2}$ Centre for Biotechnology, Nehru Science Centre, University of Allahabad, Allahabad, India
}

\begin{abstract}
Cytokine behavior of T-lymphocytes is not very clear when a patient is co-infected with Leishmania donovani and HIV. To achieve this we studied groups of patients comprising of VL infected, HIV infected and HIV-VL co-infected cases. As compared to lone infections by either of the infecting agent, the co-infection cases showed greatly diminished CD4 T-cell counts and slightly enhanced values of cytokines (IFN $\gamma$ and IL4). The effect of $63 \mathrm{KDa}$ antigenic fraction of $L$. donovani, previously reported by our group as having potential immunoprophylaxis effects, was also studied for its effect on T-cell cytokine pattern in the co-infection cases. It was interesting to find that this antigenic fraction showed an increase in the proportion of CD4 T-cells secreting IFN $\gamma$ in both VL (alone) and HIV-VL co-infection groups.
\end{abstract}

Key words: Leishmania donovani, HIV, visceral leishmaniasis (VL), immunoprophylaxis, cytokines

\section{INTRODUCTION}

The Visceral Leishmaniasis infection affects many individuals worldwide and clinical resistance to the drug of first choice-pentavalent antimonials, is also reported ${ }^{[1]}$. The VL patients remain immune to reinfection, unless the immune system is suppressed as a result of other infections such as human immunodeficiency virus type I (HIV I) infection ${ }^{[2]}$ in which case the visceral disease may re appear. There are clear indications that Th- 1 response of $\mathrm{CD} 4+\mathrm{T}$ cells is protective and easy to be induced and maintained in these patients infected with Leishmania donovani ${ }^{[3]}$. The identification and evaluation of several important Leishmanial antigens which preferentially stimulate a Th1 response rather than a Th2 response against Leishmania may be vital to develop a vaccine strategy for effective control of the disease. However, the spread of HIV infection in many of the VL cases are continuously reported ${ }^{[3-5]}$. Both HIV and Leishmania exert several overlapping effects on immune cells and their effecter functions ${ }^{[6]}$. This necessitates, therefore, a revival of works on defined antigens, particularly through examining their impact on HIV-driven immunological responses. One stumbling block in the path towards effective control via vaccination has been the problem of identifying the immunological mechanisms, which these antigens may target, particularly those that underlie $\mathrm{T}$ cell unresponsiveness and accompanies the disease. Several defined antigens of Leishmania, i.e. dp72, gp63, gp46, Leishmania eukaryotic initiation factor (LeIF) and lipophosphoglycan-associated proteins have been studied but all attempts to limit VL infection via vaccination whether in humans or canine have shown little, if any, success ${ }^{[7-13]}$. Glycoprotein $63(\mathrm{Gp} 63)$ is a major surface glycoprotein expressed on promastigotes and amastigotes of all Leishmania species. Reports are available to suggest that it protected resistant CBA mice against L.major infection ${ }^{[14]}$. There is further evidence that gp63 may play important role in attachment, successful presentation of Leishmania parasite on MHC class II molecule and thereafter $\mathrm{CD} 4+\mathrm{T}$ cell response in VL infection (Bimal et al unpublished data). In the present study, we have compared the $\mathrm{T}$ cell responses to soluble Leishmania donovani antigen versus gp63 protein in patients infected either with $L$ donovani alone or with an HIV co-infection.

\section{MATERIALS AND METHODS}

Source of leishmanial antigen: $L$. donovani parasites were grown at $24^{\circ} \mathrm{C}$ in Schneider's medium (Sigma, St. Louis, MO) supplemented with $20 \%$ heat inactivated fetal calf serum (GIBCO, Life Technology, India), $20 \mathrm{mM}$ L-Glutamine, 100 units $\mathrm{mL}^{-1}$ of penicillin and $50 \mu \mathrm{g} \mathrm{mL} L^{-1}$ of gentamycin at $\mathrm{pH}$ 7.4. Soluble Leishmania antigen (SLA) was prepared from late log phase promastigotes after few passages in liquid culture. Briefly $200 \times 10^{6}$ promastigotes per $\mathrm{mL}$ were washed thrice in $5 \mathrm{~mL}$ of cold sterile PBS. After 5 cycles of freeze and thaw, the suspension was centrifuged at

Corresponding Author: Dr. S. Bimal, Research Officer, Immunology Division, Rajendra Memorial Research Institute of Medical Sciences (ICMR), Agamkuan, Patna-800007, India, Tel: 06122570061 (R), Mob: 09334098137 
$10,000 \mathrm{xg}$ for $20 \mathrm{~min}$. at $4^{\circ} \mathrm{C}$ and the supernatant containing soluble Leishmania antigens were collected and stored at $-70^{\circ} \mathrm{C}$ till further use. The protein concentration was measured by Lowry's method. The potential role of many antigens in immunoprophylaxis against VL has recently been reported by our group $[15,16]$. The $63 \mathrm{kDa}$ protein antigen used in the study was derived from L. donovani promastigotes (MHOM/IN/80/Dd8). Briefly, cultured promastigotes were harvested in the late log phase (6-7days), washed thrice in cold phosphate buffered saline, $\mathrm{pH} 7.2-$ 7.4(PBS) and lysed by boiling for $5 \mathrm{~min}$. in sample buffer. Antigen extract thus prepared were subjected to SDS-PAGE using $12.5 \%$ resolution under reducing conditions ${ }^{[17]}$. Gel slice containing the antigenic proteins were then placed into a micro centrifuge tube, grinded and incubated in extraction buffer. Gel slurry was transferred to Nanosep MF device that contained Bio-inert modified nylon with polypropylene filtrate receiver and spun. Lower chamber containing protein in buffer was collected, while upper chamber of gel was rinsed and spun again to get any un-separated specific protein left in the process. A $500-\mu 1$ sample of $100 \mu \mathrm{g}$ $\mathrm{mL}^{-1}$ protein solution containing $63 \mathrm{kDa}$ protein antigenic fragment was centrifuged at 5000x $\mathrm{g}$ in Nanosep device to a final volume of $50 \mu \mathrm{l}$. Resulting retentate was checked for size and concentrated sample was recovered in two washes of $20 \mu \mathrm{l}$ de-ionized water for use into downstream application at later stages in the study.

Subjects: A total of 20 subjects (aged between 17 to 40 years) of both sexes were studied after obtaining their informed consent. It included 5 patients with acute VL from endemic areas, 5 patients of acute VL co-infected with HIV, 5 patients infected with HIV alone and 5 apparently healthy individuals who represented an endemic area. Measurement of body temperature, body weight, liver and spleen size, total and differential WBC count, haemoglobin, blood sugar, serum creatinine and prothromin, ECG and chest X-rays were performed in all cases. All the patients in the VL and co-infection group presented characteristic signs and symptoms of VL infection and diagnosis was confirmed by presence of $L$. donovani in the Giemsa stained spleen aspirate and positive serology (DAT). The serological result was further confirmed by PCR. The HIV infection in subjects with HIV alone or in co-infection with VL was confirmed by HIV EIA (Lab system Kit, Finland) and rapid test (NEVA HIV, Cadila, India) and these patients were not undergoing any treatment at the time of this study. All the healthy controls were negative for all disease symptoms and matched the diseased cases by sex and age ( \pm 2years). Any subject who had been treated for VL in the past was excluded from study.

The immunological evaluation of the reactivity of $\mathrm{T}$ lymphocytes to the leishmanial antigen in VL and HIVVL co-infection groups was carried out before commencement of treatment. These evaluations included T-cell subpopulation analysis (CD4 versus CD8), which was later corroborated with cytokine level (interferon-gamma and Interleukin-4) in culture supernatants after Leishmania specific stimulation, with whole L. donovani SLA or with SDS PAGE fractionated Leishmania antigen (63KDa). Blank controls were included in all experiments that were not given any specific stimulation.

Lymphocyte isolation and in vitro cultures: Peripheral Blood Mononuclear Cells (PBMNCs) were isolated from each of the blood samples by centrifugation through Ficoll Paque ${ }^{\mathrm{TM}}$ (Emerson Biosciences, Sweden) gradients ${ }^{[30]}$. The crude isolates of PBMNC were purified by washing in Phosphate Buffer Saline (PBS, Bangalore Genei, India) and then centrifuged (800xg, $15 \mathrm{~min}$.) over Histopaque. The PBMNC, collected from the layer immediately above Histopaque were washed thrice in PBS before being used further. All cultures were carried out using RPMI 1640 supplemented with $2 \mathrm{mM}$ L-glutamine, $10 \%$ heat inactivated LPS/endotoxin free Fetal Calf Serum (GIBCO, Life Technology, India), $5 \times 10^{5} \mathrm{mM} 2-$ mercaptoethanol and antibiotics (100U $\mathrm{mL}^{-1}$ Penicillin, $50 \mu \mathrm{g} \mathrm{mL} \mathrm{m}^{-1}$ Gentamycin and $100 \mu \mathrm{g} \mathrm{mL} \mathrm{mL}^{-1}$ Streptomycin)(Himedia Laboratories Pvt.Ltd., India).

\section{Immunofluorescent staining to determine lymphocyte profile ex vivo and after antigen stimulation: PBMNC $\left(2 \times 10^{6}\right)$ from VL patients and} HIV co-infected VL patients were incubated with fluorescein isothiocyanate (FITC) or phycoeryhtrin (PE) labeled antibody solutions for 20 minutes at $4^{\circ} \mathrm{C}$ for $e x$ vivo staining of lymphocytes for surface markers. The antibodies used were anti-CD4-FITC and anti-CD8-PE. After staining, the preparations were washed with $0.09 \%$ sodium azide PBS, fixed with $200 \mu \mathrm{l}$ of $2 \%$ formaldehyde in PBS and kept at $4^{0} \mathrm{C}$ until data were acquired using a fluorescence-activated cell sorter (FACS). For the evaluation of the impact of antigen specific stimulation on lymphocyte profile PBMNC $\left(2 \times 10^{6}\right)$ from VL patients and HIV co-infected VL patients were pulsed with $L$. donovani parasite (50:1 ratio) and cultured in the presence of $10 \mu \mathrm{g}$ SLA or 20 $\mu \mathrm{g}$ of $63 \mathrm{KDa}$ L. donovani antigens. Unstimulated control cultures were set up in parallel to obtain the background data in the absence of any particular stimulation. All cultures were maintained at $37{ }^{\circ} \mathrm{C}$ in a water saturated air atmosphere containing $5 \% \mathrm{CO}_{2}$ in air. Cultured cells were later stained with labeled antibodies specific for different human cell surface antigens (anti-CD4-FITC or anti-CD8-PE) as indicated above.

Cytoplasmic cytokine assay: PBMNC were analyzed for the expression of intracellular cytokines as described below. Briefly, about $2.0 \times 10^{6}$ cells were cultured in $24-$ well plates in $1 \mathrm{~mL}$ cultures for $24 \mathrm{~h}$ with either medium 
alone, $63 \mathrm{kDa}$ antigen (at $20 \mu \mathrm{g} \quad \mathrm{mL}^{-1}$ final concentration), SLA (at $10 \mu \mathrm{g} \mathrm{mL}^{-1}$ final concentration) or a positive control of $20 \mu \mathrm{g} \mathrm{mL} \mathrm{m}^{-1}$ PHA.After stimulation period of two hours all the cultures, except the control, were pulsed with Leishmania donovani. Brefeldin-A $\left(1 \mu \mathrm{g} \mathrm{mL}^{-1}\right)$ was added to culture during the last 4-hrs of culture to impair protein secretion by the golgi complex. The cells were later harvested using ice cold PBS plus azide, stained for CD4 surface markers using anti-CD4-PE antibodies and fixed with $2 \%$ formaldehyde. The fixed cells were permeabilized with a solution of saponin and stained for IFN-gamma using FITC-labeled antibodies. Isotype control panels (FITC and PE-labeled immunoglobulin control antibodies) were run in parallel to all experiments. Unbound antibodies were removed by washing the cells twice with wash buffer before each sample was resuspended in $450 \mu \mathrm{l}$ stain buffer containing $1 \%$ paraformaldehyde for examination of fluorescence in a FACS Calibur flow cytometer.

Flow cytometric analysis of samples: Lymphocytes were analyzed for expression of surface markers and intracellular cytokines using the Cell Quest software on a FACS Calibur flow cytometer. Limits for the quadrant markers were always set based on negative populations and isotype controls. For analysis of CD4 and CD8positive lymphocytes, quadrants were always set for CD4 and CD8 high populations so as not to include CD4 low-positive monocytes and macrophages and CD8 low-positive NK cells respectively.

Statistical analysis: All experiments were carried out in triplicate with two sets of observations taken in each case. All data were analyzed for statistical significance using the Student's t-test.

\section{RESULTS AND DISCUSSION}

As illustrated in Table 1, the CD4+ T cell counts are markedly reduced in all the groups of patients $(\mathrm{p}<0.01)$. Leishmania infection seems to cause reduction in the number of $\mathrm{CD} 4+\mathrm{T}$ cells and a coinfecting HIV further enhances this effect. This observation is quite in consent with the previous reports on lymphocyte profile in VL and co-infection cases ${ }^{[18-}$ ${ }^{20]}$. The CD8+ T cell counts showed varied patterns in all the three groups. It was lower than healthy control in the VL cases but was higher in both HIV and coinfection cases. The resulting $\mathrm{CD} 4 / \mathrm{CD} 8$ ratio was greatly reduced in both HIV and co-infection cases. Change observed in the CD4/CD8 ratio in VL cases was not significant in comparison to the healthy values for the same.
Table 1: Immunological profile in HIV cases co-infected with VL

\begin{tabular}{lllll}
\hline Parameter & HIV & HIV+VL & VL & Control \\
\hline CD4 & 325.1 & 162.33 & 453.00 & 1099 \\
& \pm 254.09 & \pm 144.60 & \pm 265.80 & \pm 429.06 \\
CD8 & 1304.1 & 840.33 & 222 & 653 \\
& \pm 683.40 & \pm 295.43 & \pm 96.85 & \pm 287.58 \\
CD4/CD8 & 0.230 & 0.298 & 2.153 & 2.046 \\
& \pm 0.171 & \pm 0.180 & \pm 1.062 & \pm 1.66 \\
IFN $\gamma$ & 174.1 & 175.78 & 135.80 & 105.22 \\
& \pm 127.3 & \pm 14.87 & \pm 36.92 & \pm 4.65 \\
IL-4 & 174.00 & 207.15 & 104.235 & 16.387 \\
& \pm 69.27 & \pm 8.295 & \pm 36.291 & \pm 0.358
\end{tabular}

$\mathrm{CD} 4$ and $\mathrm{CD} 8$ cell counts are expressed in cells $/ \mathrm{mL}$; cytokine concentrations are expressed as $\mathrm{pg} / \mathrm{mL}$ (values expressed as mean \pm S.D.) CD4 and CD8 count (expressed as cells $/ \mathrm{mL}$ ) was done using Cell Quest Software of Flow-Cytometry. Cytokine concentrations in the patient sera have been expressed as $\mathrm{pg} / \mathrm{mL}$. The levels of $\mathrm{CD}^{+}{ }^{+} \mathrm{T}$ cells and $\mathrm{CD}^{+} \mathrm{T}$-cells in the co-infection group differs considerably from VL or HIV infection cases alone .The CD4+ T-cell count is greatly diminished in all the three groups, being most marked in HIVVL co-infection cases. The CD8+ T-cell counts showed varied patterns in all the three groups. It was lower than control in the VL cases but was higher in both HIV and in co-infection cases. Infection with HIV, either alone or in co-infection with $L$. donovani seems to greatly alter the $\mathrm{CD} 4 / \mathrm{CD} 8$ ratios, reducing them greatly in comparison to the healthy control group. Concentrations of cytokines showed remarkable variations within the groups studied (discussed in text).

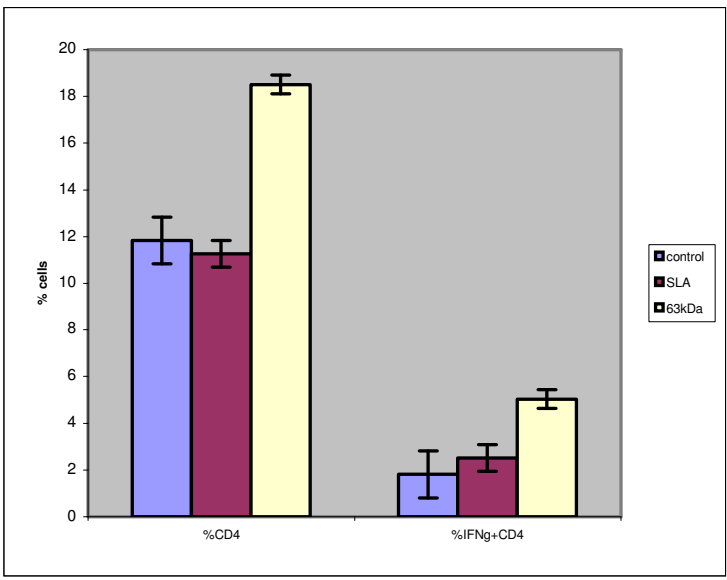

Fig. 1: Interferon gamma response induced by $63 \mathrm{kDa}$ antigenic fraction stimulation in cases of Visceral Leishmaniasis. PBMNCs $\left(2 \times 10^{6}\right.$ cells $\left./ \mathrm{mL}\right)$ incubated in RPMI-1640 medium supplemented with $20 \%$ FCS were stimulated with SLA (Soluble Leishmania Antigen) from L. donovani $(10 \mu \mathrm{g})$ or $63 \mathrm{kDa}$ protein $(10 \mu \mathrm{g})$ at $37^{\circ} \mathrm{C}$ in $5 \% \mathrm{CO} 2$ for 24 hours. The cells were later harvested, stained for CD4 surface markers and intracellular interferon gamma using appropriate antibodies and analyzed using a flow cytometer. While SLA stimulation failed to induce any significant impact on the frequency of $\mathrm{CD} 4$ cells and interferon gamma release, the $63 \mathrm{kDa}$ antigen increased both the frequency of CD4 cells and also their expression of the cytokine, IFN-gamma by significant amounts 


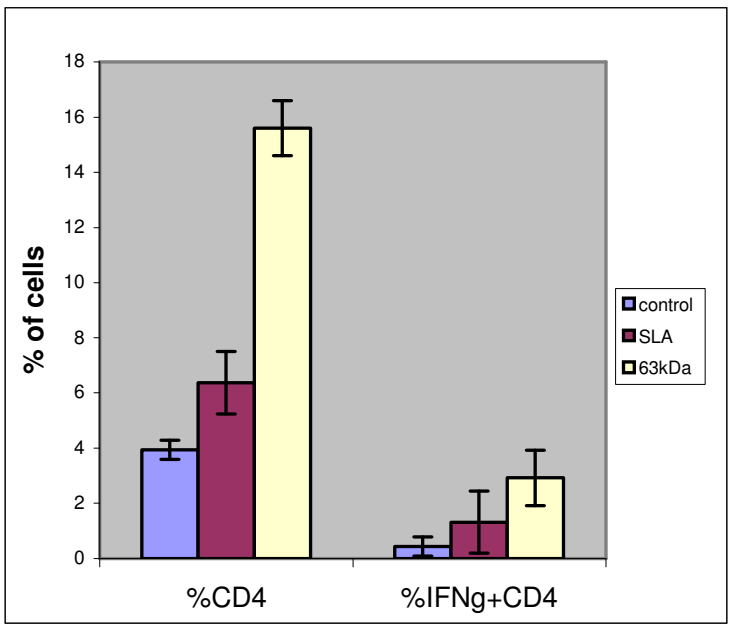

Fig. 2: Impact of $63 \mathrm{kDa}$ antigenic fraction stimulation on CD4 population and IFN-gamma release in cases of VL-HIV Coinfection. PBMNCs $\left(2 \times 10^{6}\right.$ cells $\left.\mathrm{mL}\right)$ incubated in RPMI1640 medium supplemented with $20 \%$ FCS were stimulated with SLA (Soluble Leishmania Antigen) from L. donovani $(10 \mu \mathrm{g})$ or $63 \mathrm{kDa}$ protein $(10 \mu \mathrm{g})$ at $37^{\circ} \mathrm{C}$ in $5 \% \mathrm{CO}_{2}$ for 24 hours. The cells were later harvested, stained for CD4 surface markers and intracellular interferon gamma using appropriate antibodies and analyzed using a flow cytometer. While SLA stimulation failed to induce any significant impact on the frequency of CD4 cells and interferon gamma release, the $63 \mathrm{kDa}$ antigen increased both the frequency of CD4 cells and also their expression of the cytokine, IFN-gamma

The serum levels of Th1 and Th2 cytokines, namely interferon gamma and interleukin-4 respectively, were also measured. The increase observed in interferon -gamma levels produced in all patient groups was insignificant when compared to control ( $p>0.5)$. The high levels of IFN-gamma in VL, HIV and co-infection group compared to healthy control group have also been reported earlier in many studies ${ }^{[21-23]}$. When compared within groups no statistically significant difference was observed, although co-infection group recorded a higher IFN gamma value than VL (alone) group. As healthy subjects had no prior exposure to the parasite, there was no question of antigen presentation and hence IFNgamma level was low. Interferon gamma, usually produced by the CD4 $\mathrm{T}$ cells, is the key mediator in promoting the cellular immune response activation in human VL patients. Interestingly, HIV-VL group produced higher IFN-gamma than VL (alone) group. It appears that apart from CD4+, other cells such as CD8+ $\mathrm{T}$ cells also participated in IFN-gamma production resulting in an increased IFN-gamma release in coinfection group compared to VL (alone) group. On the other hand, interleukin-4 (IL-4) produced in all patient groups was significantly higher when compared to healthy control $(\mathrm{p}<0.01)$. Within groups, co-infected patients recorded a much-enhanced IL-4 production in comparison to VL $(\mathrm{p}<0.01)$. HIV cases produced lesser IL-4 compared to co-infection cases but it was statistically insignificant $(\mathrm{p}<0.20)$. A more pronounced increase observed in IL-4 levels in all the three groups of patients, provides support for association of this cytokine with pathogenicity of the disease concerned.

It is known that VL infection is marked by profound immunosuppression in the form of lack of Tcell responsiveness to Leishmania antigen ${ }^{[18,22,24,25]}$, but there is little data regarding the T-lymphocyte behavior for cytokine production in HIV-VL co infection cases. It is also known that preferential expansion of either one of the two subsets of CD4+ T cell, Th1 (IFN-gamma and IL- 2 releasing cells) or Th2 (IL-4, IL-5, IL-10 releasing cells) dictate the outcome of Leishmanial infection ${ }^{[26-28]}$. The failure to resolve the disease is largely attributed to this unresponsiveness of $\mathrm{T}$ cells for induction of a protective response. Moreover, relatively little is known regarding the extent to which these cytokines are implicated in supporting HIV infection in VL patients. The present study demonstrated that the elevation in the levels of IL-4 was about two-fold higher in the co-infection group than in the VL cases. Our results with IL-4 are thus further advancement to the previous reports where it has been suggested that HIV-I inhibits Leishmania induced lymphocyte proliferation and that TNF-alpha secretion is important in this process ${ }^{[6] .}$ Further studies are required to elucidate the mechanism through which IL-4 may up-regulate HIV gene expression in a VL patient.

We further studied the proliferative responses of CD4+ $\mathrm{T}$ cells and also their capacity to produce interferon gamma in response to soluble Leishmania antigen (SLA) and the $63 \mathrm{kDa}$ polypeptide fraction. SLA stimulation failed to increase CD4+ $\mathrm{T}$ cell counts $(11.27 \% \pm 0.77)$ in comparison to unstimulated control $(11.83 \% \pm 1.14)$. It also failed to induce significant increase in interferon gamma production by $\mathrm{CD} 4+\mathrm{T}$ cells $(2.51 \% \pm 0.36)$ as against the control figure of $1.81 \% \pm 0.057$ (Fig. 1). This was true in both VL and HIV-VL co-infection cases. This observation complies with the previous reports of $\mathrm{T}$ cell unresponsiveness in VL and HIV-VL cases ${ }^{[29]}$.

Further studies with the $63 \mathrm{kDa}$ polypeptide fraction from $L$. donovani promastigotes indicated its potential to override this immunosuppression induced by infection in VL cases with or without HIV co-infection.

In the $\mathrm{VL}$ group, $63 \mathrm{kDa}$ stimulation was observed to induce significant increase in $\mathrm{CD} 4+\mathrm{T}$ cell population. The frequency of $\mathrm{CD} 4+\mathrm{T}$ lymphocytes increased from $11.83 \% \pm 1.14$ in control to $18.51 \%$ $\pm 0.44(\mathrm{p}<0.02)$. This antigen specific stimulation was also capable of overcoming the immunosuppression for IFN-gamma production from $\mathrm{T}$ cells. The frequency of IFN-gamma+-CD4 cells was as low as $1.81 \% \pm 0.05$ in unstimulated controls and increased to $5.035 \% \pm 0.1$ upon 63kDa specific stimulation ( $\mathrm{p}<0.05)$ (Fig. 1).

Moreover, the $63 \mathrm{KDa} L$. donovani polypeptide fraction showed to be equally potent in increasing the frequency of CD4+ T-cell in the HIV-VL co-infection 
group of patients. While SLA stimulation caused a less significant increase from $3.94 \% \pm 1.13$ in control to $6.37 \% \pm 2.61$, stimulation with $63 \mathrm{kDa}$ antigen induced an almost four-fold increase to $15.6 \% \pm 4.68(\mathrm{p}<0.05)$ (Fig. 2). A remarkable increase was also induced in the interferon gamma response from CD4+ T-cells upon antigen specific stimulation. $2.92 \% \pm 0.91$ cells were shown positive for IFN-gamma as compared to only $0.435 \% \pm 0.35$ in unstimulated controls $(\mathrm{p}<0.02)$. The results presented by us clearly identify an important immunomodulatory role of the $63 \mathrm{kDa}$ antigenic fraction of Leishmania donovani promastigotes.

Control of the visceral infection requires identification of such Leishmania components that can potentially stimulate the protective immune response in $\mathrm{VL}$ patients. In the wake of the increasing occurrence of HIV-VL co-infection cases, it is further necessary to identify potential prophylactic agents that may be equally efficient in supporting the protective cellular responses in VL cases with or without HIV co-infection. Our report on $63 \mathrm{kDa}$ antigen with a revelation that it may be instrumental in overcoming the paucity of CD4+ T-cell and the unresponsiveness of these cells for IFNgamma release, places it as a promising candidate with a vaccine prospect.

\section{ACKNOWLEDGEMENTS}

We express our thanks to the Council for Scientific and Industrial Research (CSIR), India for the financial assistance. Technical services rendered by Mr. Arvind Prasad, Division of Immunology, RMRIMS is highly acknowledged.

\section{REFERENCES}

1. Ouellette, M. and B. Papadopoulou, 1993. Mechanisms of drug action in Leishmania. Parasitol. Today, 9: 150.

2. Alvar, J., 1994. Leishmaniasis and AIDS coinfection: The Spanish example. Parasitol. Today, 10: 160-163.

3. DasGupta, B., K.R., Choudhary, S, Ganguly, P.K. Sinha, S. Bimal, P. Das and S. Roy, 2003. Upregulation of interferon-gamma receptor-1 in monocytes of kala-azar patients and THP1 cells after treatment with anti-leishmanial drugs. Ann. Trop. Med. Parasitol., 97: 245-257.

4. Thakur, C.P., P.K. Sinha, R.K. Singh, S.M. Hassan and S. Narain, 2000. Miltefosine in a case of visceral leishmaniasis with HIV co infection and rising incidence in India. Trans. Royal Soc. Trop. Med. Hyg., 94: 696-697.
5. Pandey, K., P.K. Sinha, V.N.R. Ravidas, N. Kumar, N. Verma, C.S. Lal, S. Bimal, D. Sur and S.K. Bhattacharya, 2005. Nexus of infection with human immunodeficiency virus, pulmonary tuberculosis and visceral leishmaniasis: A case report from Bihar, India. Am. J. Trop. Med. Hyg, 72: 30-32.

6. Wolday, D., H. Akuffo, A. Demissie and S. Britton, 1999. Role of Leishmania donovani and its lipophosphoglycan in CD4+ T-cell activation induced Human Immunodeficiency Virus Replication. Infect. Immun., 67: 5258-5264.

7. Saldarriaga, O.A., B.L. Travi, W. Park, L.E. Perez and P.C. Melby, 2006. Immunogenicity of a multicomponent DNA vaccine against visceral leishmaniasis in dogs. Vaccine, 24: 1928-1940.

8. Nogueira, F.S., M.A. Moreira, G.P. Borja-Cabrera, F.N. Santos, I. Menz, L.E. Parra, Z. Xu, H.J. Chu, C.B. Palatnik-de-Souza and M.C. Luvizotto, 2005. Leishmune vaccine blocks the transmission of canine visceral leishmaniasis: Absence of Leishmania parasites in blood, skin and lymph nodes of vaccinated exposed dogs. Vaccine, 23: 4805-10.

9. Melby, P.C., G.B. Ogden, H.A. Flores, W. Zhao, C. Gelgmacher, N.M. Biediger, S.K. Ahuja, J. Uranga and M. Melendez, 2000. Identification of vaccine candidates for experimental visceral leishmaniasis by immunization with sequential fractions of cDNA expression library. Infect. Immun., 68: 5595-602.

10. Webb, J.R., A. Campos-Neto, P.J. Ovendale, T.I. Martin, E.J. Stromberg, R. Badaro and S.G. Reed, 1998. Human and murine immune responses to a novel Leishmania major recombinant protein encoded by members of a multicopy gene family. Infect. Immun., 66: 3279-3289.

11. Skeiky, Y.A.W., J.A. Guderian, D.R. Benson, O. Bacelar, E.M. Caravalho, M. Kubin, R. Badaro, G. Trinchieri and S.G. Reed, 1995. A recombinant Leishmania antigen that stimulates human peripheral blood mononuclear cells to express interleukin-12. J. Exp. Med., 181: 1527-1537.

12. Rachamin, N. and C.L. Jaffe, 1993. Pure protein from Leishmania donovani protects mice against both cutaneous and visceral Leishmaniasis. J. Immunol., 150: 2322.

13. Russo, D.M., J.M.Jr. Burns, E.M. Caravalho, R.J. Armitage, K.H. Grabstein, L.L. Britton, W.R. McMaster and S.G. Reed, 1991. Human T cell responses to gp63, a surface antigen of Leishmania. J. Immunol., 147: 3575-3580.

14. Yang, D.M., N. Fairweather, L. Button, W.R. McMaster, L.P. Kahl and F.Y. Liew, 1990. Oral Salmonella typhimurium vaccine expressing a major leishmanial surface protein (gp63) preferentially induced Th1 cells and protective immunity against leishmaniasis. J. Immunol., 145: 2281-2285. 
15. Bimal, S., Pranati, P.K. Sinha, A.K. Gupta, N. Verma, S.K. Singh, S. Sundaram, S., K. Kishore, S.K. Bhattacharya and P. Das, 2004. Screening the antigenic components of Leishmania donovani species recognized by sera from human patients with active visceral leishmaniasis (VL), with special emphasis on identification of potential antigen/s for use in future vaccination programs. J. Immunol. Immunopathol. 6(S-1): 72-73.

16. Pranati, S. Sundaram and S. Bimal, 2005. Study of the antigenic components of Leishmania donovani isolates towards identification of potential antigen/s for use in diagnosis and vaccination programmes. Proceedings of the International Training and Research in Emerging Infectious Diseases, Asian Regional Workshop on Intracellular Pathogens at New Delhi, on 8-11 March, p: 97.

17. Laemmli, U.K., 1970. Cleavage of structural proteins during assembly of the head of bacteriophage T4. Nature, 227: 680-685.

18. Ghose, M.K., A.K. Ghose and M. Addy, et al., 1996. Subpopulation of T-lymphocytes in the peripheral blood and lymph nodes of Indian Kalaazar patients. Medical Microbiol. Immunol., 185: 183-187.

19. Nigro, L., C. Bruno, P. Wolfgang, B. Jens, C. Jindrich, P. Filippo, R. Russo, H.W. Doerr and A. Nunnari, 1999. In vitro production of type 1 and type 2 cytokines by peripheral blood mononuclear cells from subjects coinfected with human immunodeficience virus and Leishmania infantum. Am. J. Trop. Med. Hyg., 60: 142-145.

20. Sinha, P.K., S. Bimal, S.K. Singh, K. Pandey, D.N. Gangopadhyay and S.K. Bhattacharya, 2006. Preand post- treatment evaluation of immunological features in Indian visceral leishmaniasis (VL) patients with HIV co-infection. Indian J. Med. Res., 123:197-202.

21. Medrano, F.J., C. Rey, M. Leal, C. Canavate, A. Rubio, A. Sanchez-Quijano, J. Alvar and E. Lissen, 1998. Dynamics of serum cytokines in patients with visceral leishmaniasis and HIV-1 co-infection. Clin. Expl. Immunol., 114: 403-7.
22. Hailu, A., T. van der Poll, N. Berhe and P.A. Kager, 2004. Elevated plasma levels of interferon (IFN-) gamma, IFN-gamma inducing cytokines and IFN-gamma inducible CXC chemokines in visceral leishmaniasis. Am. J. Trop. Med. Hyg., 71: 561-7.

23. Caldas, A., C. Favali, D. Aquino, V. Vinhas, J. van Weyenbergh, C. Brodskyn, J. Costa, M. BarralNetto and N. Barral, 2005. Balance of IL-10 and interferon-gamma plasma levels in human visceral leishmaniasis: implications in the pathogenesis. BMC Infect. Dis., 19: 113.

24. Kumar, R., K. Pai and S. Sundar, 2001. Reactive oxygen intermediates, nitrite and IFN-gamma in Indian visceral leishmaniasis. Clin. Expl. Immunol., 124: 262-5.

25. Lehmann, J.K., K.H. Eussle, L. Lehmann, A. Emmendorf and M.L. Lohman-Mathes, 2000. The capacity to produce Interferon-gamma rather than the presence of IL-4 determines resistance and degree of susceptibility to Leishmania donovani infection in mice. J. Interferon Cytokine Res., 20: 63-77.

26. Sunder, S., G.S. Reed, S. Sharma, A. Mehrotra and H.W. Murray, 1997. Circulating T-helper 1(Th1) cell and Th2 cell associated cytokines in Indian patients with visceral leishmaniasis. Am. J. Trop. Med. Hyg., 56: 522-535.

27. Reiner, S.L. and R.M. Locksley, 1995. The regulation of immunity to Leishmania major. Ann. Rev. Immunol., 13: 151-177.

28. Miralles, G.D., M.Y. Stockle, D.F. McDermott, F.D. Finkelman and H.W. Murray, 1994. Induction of Th1 and Th2 cell associated cytokine in experimental Visceral Leishmaniasis. Infect. Immun., 62: 1058-1063.

29. Wolday, D., N. Berhe, S. Britton and H. Akuffo, 2000. HIV-1 alters T helper cytokines, interleukin12 and interleukin-18 responses to the protozoan parasite Leishmania donovani. AIDS, 14: 921-9.

30. Boyum, A., 1968. Isolation of mononuclear cells and granulocytes from human blood. Scandinavian J. Clin. Lab. Invest. Suppl., 21: 77-89. 